\title{
Effects of Participation in Inclusive Physical Activity on Social Skills of Individuals With Autism Spectrum Disorder
}

\author{
Sibel Nalbant \\ Correspondence: Assist. Prof. Dr. Sibel Nalbant, Alanya Alaaddin Keykubat University, Faculty of Sport Sciences, \\ Turkey.
}

Received: July 22, 2018

doi:10.11114/jets.v6i12.3789
Accepted: October 2, $2018 \quad$ Online Published: November 26, 2018

URL: https://doi.org/10.11114/jets.v6i12.3789

\begin{abstract}
In the National Standards Report (2015) of the National Autism Centre, participation in physical activities in the education of children with autism spectrum disorder (ASD) is defined to be a promising intervention method (scientific base being formed). On the other hand, as a result of the regulations on inclusion, there has been a rapid increase in the number of children with special needs studying in general education classes together with their peers. Based on these two tendencies in recent years, the objective of this study was determined to be the effect of participation in inclusive physical activity on social skill in children and youth with ASD. The participants of the study were 55 children with ASD between the ages of 6 and 26 including 15 girls and 40 boys who participated in the inclusive physical activity (IPAC) program with their peers having typical development for two days a week and 45 minutes a day during 3 months within the scope of the "Inclusive Physical Activity Centre" project of the Istanbul Gedik University. The applied IPAC program involved peer participation and supported specialized movement skills and development of physical and motor capabilities. The data of this research were gathered using a Personal Information Form and Autism Social Skill Profile (ASSP) by face-to-face interviews with the parents of the participants. The study was designed with the single group pretest-posttest model of quasi-experimental studies. The study after IPAC determined a significant difference in the subscales of the scale and in the ASSP-Total score $(\mathrm{p}<0.05)$. The findings of this study demonstrated the effectiveness of inclusive physical activity on the social skills of individuals with ASD. For the similar future studies, the use of the design with control group and supporting it with qualitative data for the detailed explanation of the results obtained by quantitative approach are recommended.
\end{abstract}

Keywords: autism spectrum disorder, physical activity and social skill

\section{Introduction}

Human kind starts communication with others and continues to grow in social interaction. This experiences provide contribution to the social, mental and psychological development of individuals and reveal their self realization feeling in a healthy manner. Even individuals without any health problems in the society having normal development face problems in social development (Yavuzer, 2002). Physical activity (PA) is a necessity for all people today and along with developing technology, has also led to the development of new training equipment and methods (Nalbant, 2018). As a method, PA is a tool for people's social interaction and it is also important for increasing the life qualities of the individuals with special needs and for acquiring social skills. Another important issue is that the PA environment joined by the individuals with special needs should provide high efficiency. For this purpose, the PA environment should be inclusive based on the statement in the Article 30 of the Convention of the United Nations on the Rights of Persons with Disabilities which reads "equal participation of children with special needs in sporting activities with their peers". Another detail is that the physical activities to be implemented in inclusive environment should be planned in a manner meeting the activity needs of every kind of participants.

The term "inclusion" with regards to special education was first introduced in the "Salamanca Declaration" published after the World Conference held in 1994 (United Nations Educational, Scientific and Cultural Organization[UNESCO], 1994). As stated in this declaration, experiences in several countries reveal that the most effective participations of the children with special needs can be possible within inclusive schools serving all children. It is believed that this is the only way to ensure educational progress and social inclusion (Castillo Rodríguez \& Garro-Gila, 2015). Inclusive physical activity (IPAC) has a facilitating nature for gaining social skills. ASD is defined within the context of of special requirements and it is a developmental and neurological disorder which emerges in the age group of 0-3 years. The "social interaction" and "communication" areas which contain the diagnosis criteria in DSM-IV-TR are combined 
under "social interaction/communication deficiencies" in DSM-5. The reason is that ASD is distinguished with difficulty to make an eye contact, problems in starting social communication, problematic behaviours in keeping the speech, problems in mutual interactions and plays with the peers, difficulty in adaptation to changes, and problematic behaviours in areas including verbal and non-verbal social interaction behaviours (Alvarez \& Reid, 2013; Carter et al., 1998). All these behavioural problems cause negative experiences in the participation of children with ASD in physical activities. In the National Standards Report (2015) of the National Autism Centre, participation in physical activities in the education of children with autism spectrum disorder (ASD) is defined to be a promising intervention method (scientific base being formed). On the other hand, practices for providing children with ASD with education in inclusive environment together with their able peers are gradually increasing (Bruder, 2010; Demeris, Childs, \& Jordan, 2007; Henninger, Gupta, \& Vinh, 2014; Harrower \& Dunlap, 2001; Hundert, 2009; Yarımkaya, 2017; Lermi, 2016) In this aspect, it can be considered that the IPAC environments are an important instrument for transforming the negative peer attitudes of children with ASD that hinder participation in physical activity.

The findings of the researches on the participation of the children with ASD in physical activities and sporting activities indicate that physical activities and sports create opportunities for social interaction (Berkeley, Zittel, Pitney,V.Stacia \& Nichols, 2001; Pan, 2011, Pan, Tsai, \& Hsieh, 2011; Pan, 2010), reduce stereotypic behaviors, (Lippold \& Burns, 2009; Levinson \& Reid, 1993; Prupas \& Reid, 2001), contribute to the development of self management skill and develop physical fitnes (Borremans, Rintala, \& McCubbin, 2010; Duronjic \& Valkova 2010; Harbin, 2012; Hatton, 2012; Pan, 2007; Pan, 2008; Pan, 2009; Pan, Tsai, \& Hsieh, 2011; Reid \& O’Connor, 2003; Sandt, \& Frey, 2005; Todd \& Reid, 2006; Yanardağ, Ergun, \& Y1lmaz, 2009; Yanardag, Ergun, Yılmaz, Aras, \& Konukman, 2011; Yılmaz, Yanardağ, Birkan, \& Bumin, 2004).

Studies on sports and physical activity in children with ASD demonstrated some positive effects, however, it is considered that this issue is not addressed sufficiently (Todd \& Reid, 2006). Studying the effect of participation in inclusive physical activity in children with ASD on social skills has been determined to be our main subject.

\section{Method}

\subsection{Research Model}

This study has been designed with the single group pretest-posttest model of quasi-experimental studies. In the present study, which collects data by the use of scale among the quantitative data collection instruments, the independent variable is participation in inclusive physical activities while the dependent variable is the social skill levels of the children and youth with ASD.

\subsection{Study Group}

The participants of the study are 55 children and youth volunteers with ASD between the ages of 6 and 26 including 15 girls and 40 boys who participated in the inclusive physical activity (IPAC) program with their peers with typical development for two days a week and 45 minutes a day during 3 months within the scope of the "Inclusive Physical Activity Centre" project of the Istanbul Gedik University.

- The criteria of participation of the children and youth with ASD: (a) having an official diagnosis of ASD, (b) having an inclusive physical activity education for 2 days a week for 3 months, (c) the Informed Consent Form signed by his or her guardian.

- Criteria for excluding the children and youth with ASD from the study: (a) quitting participation in the study during the research period, (b) a health problem that would hinder participation in the study during the research period.

\subsection{Data Collection Instruments}

Personal Information Form (PIF); PIF has been developed by the researcher to reach information about different variables (age, sex, diagnosis) of the participants.

Autism Social Skills Profile (ASSP); ASSP was created by Bellini and Hopf in 2007 to reveal the deficiencies of the children and youth diagnosed with ASD in the fields of social skills, to prepare and develop intervention programs that are suitable for them. The ASSP scale includes more comprehensive social skill test items than the other scales and is based on the inadequacies of the social skills of the children diagnosed with ASD. The ASSP can be completed by a parent, a teacher, or any other adult who is familiar with the child's social behavior. The ASSP may be administered by professionals (psychologists, psychiatrists, social workers, counselors, or speech-language pathologists) wishing to design and implement social skills interventions. The scale consists of 41 items in total with 41 points being the lowest and 164 points being the highest point that a person can get from the scale. Items on the ASSP are rated on a 4-point Likert scale ranging from never to very often. Each response on the scale has a corresponding numerical value (from 1 to 4), with high scores corresponding to positive social behaviors, to produce a total score of social functioning. The majority of items on the ASSP are written as positive behaviors (e.g., "Joins in activities with peers"); some items, 
however, are written as negative behaviors (e.g., "Makes inappropriate comments"). These "negative" items are reverse scored so that a response of very often would provide a score of 1 .

The ASSP contains three subscales, labeled The Social Reciprocity, The Social Participation/Avoidance and The Detrimental Social Behaviors.

- The Social Reciprocity $(S R)$ subscale involves skills that are necessary to maintain a successful reciprocal social interaction. The items cover both explicit reciprocal behaviors and behaviors that indicate a child's ability to consider the thoughts, feelings, and interests of others or to take another person's perspective. The SR subscale consists of 15 items and the lowest score that can be taken from this sub-dimension is 15 while the highest score is 60 .

- The Social Participation/Avoidance (SPA) subscale contains items related to social engagement and withdrawal from social participation. Items represent less active maintenance of reciprocal social interactions. The SPA subscale consists of 14 items and the lowest score that can be taken from this sub-dimension is 14 while the highest score is 56 .

- The Detrimental Social Behaviors (DSB) subscale includes items that represent socially inappropriate behaviors and behaviors that could contribute to negative peer experiences. Problems on this subscale may lead directly to adverse social interactions. The SPA subscale consists of 12 items and the lowest score that can be taken from this sub-dimension is 12 while the highest score is 48 .

Demir (2014) obtained a significant positive correlation between the SR and SPA subscale. In addition, the author found that the correlation between the DSB subscale and other subscales is low and inverse. As Bellini and Hopf (2007) stated, it can be argued that the DSB subscale is an independent scale because it contains negative social behaviors. As a result, subscale of SR and SPA include positive social behaviors, DSB subscale includes negative social behaviors and is scored inversely (Demir, 2014; Bellini \& Hopf, 2007).

\subsection{Data Collection Process}

The study was started after getting approval of the Ethics Committee of the Istanbul Gedik University. Data was collected through face-to-face interviews with the parents of the children and youth with ASD who regularly participated in the IPAC educations for 3 months between 2016 and 2017 within the scope of the project "We Are in The Active and We Are Integrated into the community; Inclusive Physical Activity Centre for the Children with Disabilities".

\subsection{The Principles of the Inclusive Physical Activity Program}

The aim of the inclusive physical activity educations participated by the children and youth with ASD under the present study is to develop fundamental movement skill (FMS) and specialized movement skills (Özer, Grenier, Nalbant, \& Hatipoğlu-Özcan, 2016). The applied IPAC program involves peer participation and supports specialized movement skills and the development of physical and motor capabilities, development of perceptual motor skills and movement skills, i.e. moving, object control and balance.

\subsection{Analysis and Interpretation of Data}

Data were analysed in SPSS version 22 with alpha $=\mathrm{p}<0.05$. Normality of distributions was assessed using Kolmogorov-Smirnov tests. Before the analysis, tests were applied on the normal distribution of the test values. As a result of the analysis, Wilcoxon signed-rank test was used because the data were not normally distributed.

\section{Findings}

The following statistical analysis results emerged when children and youth with ASD were examined with respect to different variables.

Table 1. Descriptive Properties of the Participants of the Study

\begin{tabular}{llcc}
\hline & & Number & \% \\
\hline \multirow{2}{*}{ Sex } & Girl & 15 & 27 \\
& Boy & 40 & 73 \\
Age & $6-13$ & 43 & 78 \\
& $14-26$ & 12 & 22 \\
\multirow{3}{*}{ Diagnosis } & Autism & 22 & 40 \\
& Atypical autism & 16 & 29 \\
& Chiildhood autism & 17 & 31 \\
& Total & $\mathbf{5 5}$ & $\mathbf{1 0 0}$ \\
\hline
\end{tabular}

The findings that is related to social skill levels of the children and youth with ASD;

\section{Social skill levels of the children and youth with ASD before participation in IPAC.}

In order to determine the social skill levels of the children and youth with ASD, the averages and standard deviations of the scores from the ASSP-T and the subscales were calculated and the results were given in Table 2. 
Table 2. Score Averages from the ASSP-T Test and Its Subscales

\begin{tabular}{lcc}
\hline & Number & Mean \pm Std \\
\hline ASSP-T & 55 & $87,43 \pm 6.12$ \\
Social Reciprocity & 55 & $39,12 \pm 6.87$ \\
Social Participation/Avoidance & 55 & $34,90 \pm 6.65$ \\
Detrimental Social Behaviors & 55 & $17,14 \pm 4.34$
\end{tabular}

As shown in Table 2. ASSP-T that was taken from measurement in the beginning of IPAC $(87,43 \pm 6.12)$ was compared with the highest score to get from the scale (164) and it was determined that the participants have moderate social skill qualities.

2. Social Skill Levels of the Children and Youth With ASD That Changed After Participation in IPAC

Table 3. Wilcoxon signed-rank test results of the first and last measurement from the ASSP-T and its Subscales

\begin{tabular}{|c|c|c|c|c|c|c|}
\hline Score & Groups & $N$ & $\bar{x}_{\text {sira }}$ & $\sum_{\text {sira }}$ & $z$ & $p$ \\
\hline $\begin{array}{l}\text { Social Reciprocity Subscale Scores of First and Last } \\
\text { Measurements }\end{array}$ & $\begin{array}{l}\text { Decreasing } \\
\text { Increasing } \\
\text { Equal } \\
\text { Total }\end{array}$ & $\begin{array}{l}5_{\mathrm{uc}}^{\mathrm{oa}} \\
55\end{array}$ & $\begin{array}{c}0,00 \\
98,72\end{array}$ & 347,50 & $-5,421$ & ,002 \\
\hline $\begin{array}{l}\text { Social Participation/Avoidance Subscale Scores of First and } \\
\text { Last Measurements }\end{array}$ & $\begin{array}{l}\text { Decreasing } \\
\text { Increasing } \\
\text { Equal } \\
\text { Total }\end{array}$ & $\begin{array}{l}0 \mathrm{a} \\
55^{\mathrm{b}} \\
55^{\mathrm{c}} \\
\end{array}$ & $\begin{array}{c}0,00 \\
89,56\end{array}$ & 543,50 & $-4,234$ & ,001 \\
\hline $\begin{array}{l}\text { Detrimental Social Behaviors Subscale Scores of First and } \\
\text { Last Measurements }\end{array}$ & $\begin{array}{l}\text { Decreasing } \\
\text { Increasing } \\
\text { Equal } \\
\text { Total } \\
\end{array}$ & $\begin{array}{c}0 \mathrm{a} \\
55 \mathrm{~b} \\
0 \mathrm{c} \\
55\end{array}$ & $\begin{array}{r}0,00 \\
85,45\end{array}$ & 432,50 & $-3,432$ &, 001 \\
\hline ASSP-T Scores of First and Last Measurements & $\begin{array}{l}\text { Decreasing } \\
\text { Increasing } \\
\text { Equal } \\
\text { Total }\end{array}$ & $\begin{array}{c}0 \mathrm{a} \\
55 \mathrm{~b} \\
0 \mathrm{c} \\
55\end{array}$ & $\begin{array}{c}0,00 \\
90,65\end{array}$ & 735,56 & $-6,543$ & ,001 \\
\hline
\end{tabular}

As shown in Table 3, the results of the Wilcoxon test indicate that there are statistically significant increase in the scores of the participants after IPAC with respect to Social Reciprocity Subscale $(\mathrm{z}=-5,421 ; \mathrm{p}<.01)$, Social Participation/Avoidance Subscale $(z=-4,234 ; p<.01)$, Detrimental Social Behaviours $(z=-6,543 ; p<.01)$ subscale and ASSP-T. As a result, it was determined that the social skill scores of the children and youth with ASD had a statistically significant increase after participation in IPAC.

\section{Results and Discussion}

The aim of this study is to examine the effect of regular participation in inclusive physical activity in children with autism spectrum disorder on their social skills. According to the results of this study which examined the social skills of the children with ASD that change by participation in inclusive physical activity, the average score of 55 participants was found to be $39.12(\mathrm{sd}=6.87)$ for the social reciprocity subscale, 34.90 (sd=6.65) for the Social Participation/Avoidance subscale, and $17,14(\mathrm{sd}=4.34)$ for the detrimental social behaviours subscale. Upon the comparison of the highest and lowest scores to get from the scale, it is a remarkable finding that the participants have a score $(17,14)$ near to the lowest score particularly in the detrimental social behaviours subscale (lowest:12, highest 48). The total score average of the children and youth with ASD from ASSP-T is $87.43(\mathrm{sd}=6,12)$. When the highest score to get from the scale (164) is compared to their total score from ASSP-T, it is observed that the original social skill levels of the participants are in the average value. Demir (2014), conducted a study on the social skills in children with ASD according to different variables by obtaining information through the OSBF scale from the parents and teachers of 208 children with ASD between the ages of 6 and 17 years and found that the total score average of the participants from

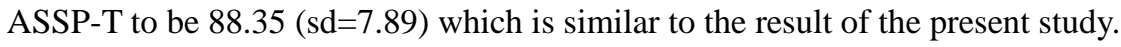

Researches from different disciplines dealing with the children with ASD argue that the most basic problem of the children diagnosed with ASD is the inadequacy of social skills and therefore the field of "social skill" should be a priority in the education of the individuals with ASD (Matson J, Matson M.L, \& Rivet, 2007). It has been observed in recent years that the teaching of social skills to the children with ASD is carried out by the use of peer supported education, video model education, activity schedules and teaching by social story which are defined to be special teaching methods (Banda, Hart \& Liu-Gitz, 2010; Chung et al., 2007; Kroeger, Schultz, \& Newsom, 2007; Matson J, Matson M.L, \& Rivet, 2007; Wang, Cui, \& Parrila, 2011). 
The increase in the prevalence of ASD required concentration on the studies to determine suitable intervention programs for these children. In the National Standards Report (2015) of the National Autism Centre, participation in physical activities in the education of children with autism spectrum disorder (ASD) is defined to be a promising intervention method (scientific base being formed). On the other hand, practices for providing children with ASD with education in inclusive environment together with their able peers are together with their able peers ally increasing (Bruder, 2010; Demeris, Childs, \& Jordan, 2007; Henninger, Gupta \& Vinh, 2014; Harrower \& Dunlap, 2001; Hundert, 2009; Lermi, 2016; Yarımkaya, 2017). The findings of the studies on the participation of the children with ASD in physical activities and sport activities indicated that the adapted programs of physical activity, exercise and sport education had a positive effect on the socialization levels of the children with ASD (Berkeley et al., 2001; Pan, 2011, Pan, 2010) and that this effect lead to positive developments in the fields of interaction with others, participation in group works and adaptation which are covered by social skills. This study found statistically significant and high difference in favour of last measurements between the scores from the subscales (social reciprocity $(z=-5,421 ; p<.01)$, Social Participation/Avoidance $(z=-4,234 ; p<.01)$, detrimental social behaviours $(\mathrm{z}=-6,543 ; \mathrm{p}<.01)$ and ASSP-T according to the findings of the comparison of the original and last measurement scores of the participants from the ASSP scale after IPAC.

As a result, it was determined that the social skill scores of the children and youth with ASD had a statistically significant increase after participation in IPAC. Although there are studies on the effect of participation in physical activity in children and youth with ASD on motor skills and physical fitness (Borremans, Rintala, \& McCubbin, 2010; Duronjic \& Valkova 2010; Harbin, 2012; Hatton, 2012; Pan, 2007; Pan, 2008; Pan, 2009; Pan, 2011; Pan, Tsai, \& Hsieh, 2011; Reid \& O'Connor, 2003; Sandt, \& Frey, 2005; Todd \& Reid, 2006; Yanardăg, Ergun, \& Y1lmaz, 2009; Yanardağ, et al., 2011; Y1lmaz, et al., 2004;) and on the effect of the planned movement skill program on limited specialized skills including bicycling and playing with ball (Doğru, Önal \& Bek, 2007; Yanardağ , Ergun, Yılmaz, \& Konukman, 2008), there are limited number of studies that examine the effect of participation in physical activity, which is defined to be a promising practice for the children with ASD, on the change in social skills. The result of the study supports the results of the other studies that revealed the importance of participation in physical activity in the development of social skills of the children with ASD (Berkeley et al., 2001; Pan, 2011, Pan, 2010).

According to the results of the present study, determination of the fact that participation in IPAC caused significant positive change in social skills is an evidence for realizing physical activity programs in inclusive environments and considering physical activity to be a practice with scientific base rather than a promising practice.

\section{Recommendations}

One of the important limitations of the study was that it didn't examine the difference according to the variables of sex and age of the children and youth with ASD. In addition, the fact that the effect of the inclusive physical activity educations on the development of language skills was not examined is another limitation based on the knowledge of strong relation between social skills and linguistic and speaking skills. It is recommended that the prospective similar studies should use control group design and the results obtained by quantitative approach should be supported by qualitative data for detailed explanation. In addition, based on the idea that there is a strong relation between social skills and linguistic and speaking skills (Bellini \& Hopf, 2007), it is recommended that the future studies should examine the language skills of the children with ASD.

\section{References}

Alvarez, A., \& Reid, S. (2013). Autism and personality: Findings from the Tavistock autism workshop. London, Routledge. https://doi.org/10.4324/9780203754399

Banda, D. R., Hart, S. L., \& Liu-Gitz, L. (2010). İmpact of training peers and children with autism on social skills during center time activities in inclusive classrooms. Research in Autism Spectrum Disorders, 4(4), 619-625. https://doi.org/10.1016/j.rasd.2009.12.005

Bellini, S., \& Hopf, A. (2007). The development of the autism social skills profile: a preliminary analysis of psychometric properties. Focus on Autism and Other Developmental Disabilities, 22(2), 80-87. https://doi.org/10.1177/10883576070220020801

Berkeley, L., Zittel, L., Pitney, V., Stacia, E., \& Nichols, E. (2001). locomotor and object control skills of children. Diagnosed with Autism. 18(4), 405-416.

Borremans, E., Rintala, P., \& McCubbin, J. A. (2010). Physical fitness and physical activity in adolescents with asperger syndrome: A comparative study. Adapted Physical Activity Quarterly, 27, 308-320. https://doi.org/10.1123/apaq.27.4.308

Bruder, M. B. (2010). Early childhood intervention: a promise to children and families for their future. Exceptional Children, 3, 339-355. https://doi.org/10.1177/001440291007600306 
Carter, A. S., Volkmar, F. R., Sparrow, S. S., Wang, J. J., Lord, C., Dawson, G., ... \& Schopler, E. (1998). The vineland adaptive behavior scales: supplementary norms for individuals with autism. Journal of autism and developmental disorders, 28(4), 287-302. https://doi.org/10.1023/A:1026056518470

Castillo, R. C., \& Garro-Gil, N. (2015). Inclusion and integration on special education. Procedia. Social and Behavioral Science, 191, 1323-1327. https://doi.org/10.1016/j.sbspro.2015.04.488

Chung, K. M., Reavis, S., Mosconi, M., Drewry, J., Matthews, T., \& Tassé, M. J. (2007). Peer-mediated social skills training program for young children with high-functioning autism. Research in Developmental Disabilities, 28(4), 423-436. https://doi.org/10.1016/j.ridd.2006.05.002

Demeris, H., Childs, R. A., \& Jordan, A. (2007). The influence of students with special needs included in grade-3 classrooms on the large-scale achievement scores of students without special needs. Canadian Journal of Education, 30, 609-627. https://doi.org/10.2307/20466655

Demir, Ş. (2014). Factors affecting social skills of autistic children. Ankara University Journal of Faculty of Educational Sciences, 47, 223-245.

Doğru, Y. S. S., Önal, Ö. B. Y., \& Bek, H. (2007). Teaching how to ride a balance wheeled bicycle to autistic children using the direct instruction method. Journal of Selcuk University Social Sciences Institute, 18(1), 245-256.

Duronjić, M., \& Válková, H. (2010). The infl uence of early intervention movement programs on motor skills development in preschoolers with autist spectrum disordes (case study). Acta Universitatis Palackianae Olomucensis. Gymnica, 40(2), 37-45.

Harbin, S. G. (2012). The effects of physical activity on engagement in young children with autism (Master's thesis). Available from ProOuest Dissertations and Theses database. (UMI No. 1516107)

Harrower, J. A., \& Dunlap, G. (2001). Including students with autism in general education classrooms: a review of effective strategies. Behavior Modification, 25(5), 762-779. https://doi.org/10.1177/01454455501255006

Hatton, L. (2012). Physical fitness, physical activity and social participation levels in children with physical and/or intellectual disability who participate in equine mounted activites (Master's thesis). Available from ProOuest Dissertations and Theses database. (UMI No. U605574)

Henninger, I. V. W. R., Gupta, S. S., \& Vinh, M. E. (2014). How do children benefit from inclusion? Chapter 3. In First steps to preschool inclusion: How to jumpstart your program-wide plan. Baltimore, MD: Paul H. Brookes Publishing Co. pp. 37-43.

Hundert, J. (2009). Inclusion of Students with Autism: Using ABA Supports in General Education. Austin, TX: Pro-Ed Inc.

Kroeger, K. A., Schultz, J. R., \& Newsom, C. (2007). A comparison of two group-delivered social skills programs for young children with autism. Journal of Autism and Developmental Disorders, 37(5), 808-817. https://doi.org/10.1007/s10803-006-0207-x

Lermi, E. (2016). Examination of the Participation of Physical Education Courses in the Integration of Autistic Students with Physical Education Teachers and Parents Perspective. (Unpublished master's thesis). University of Gedik, İstanbul, Turkey.

Levinson, J., \& Reid, G. (1993). The effects of exercise intensity on the stereotypic behaviors of individuals with autism. Physical Activity Quarterly, 10(3), 255-268. https://doi.org/10.1123/apaq.10.3.255

Lippold, T., \& Burns, J. (2009). Social support and intellectual disabilities: A comparison between social networks of adults with intellectual disability and those with physical disability. Journal of Intellectual Disability Research, 53(5), 463-473. https://doi.org/10.1111/j.1365-2788.2009.01170.x

Matson, J. L., Matson, M. L., \& Rivet, T. T. (2007). Social-skills treatments for children with autism spectrum disorders: An overview. Behavior modification, 31(5), 682-707. https://doi.org/10.1177/0145445507301650

Nalbant, Ö. (2018). The effect of suspension workout on agility and forces performance in elite basketball players. Journal of Education and Training Studies, 6(6), 128-133. https://doi.org/10.11114/jets.v6i6.3257

National Autism Center (2015). Findings and conclusions: National standards project, Phase 2. Retrieved from http://www.nationalautismcenter.org/090605-2/

Özer, D., Grenier, M., Nalbant, S., \& Hatipoğlu, Ö. G. (2016). Active life center-a Turkish model for teaching students with disabilities. Palaestra. 30(1), 49-52. 
Pan, C. Y. (2007). Objectively measured physical activity between children with autism spectrum disorders and children without disabilities during inclusive recess settings in Taiwan. Journal of Autism and Developmental Disorders, 38(7), 1292-1301. https://doi.org/10.1007/s10803-007-0518-6

Pan, C. Y. (2008). School time physical activity of students with and without autism spectrum disorders during PE and recess. Adapted Physical Activity Quarterly, 25(4), 308-321. https://doi.org/10.1123/apaq.25.4.308

Pan, C. Y. (2009). Age, social engagement, and physical activity in children with autism spectrum disorders. Research in Autism Spectrum Disorders, 3(1), 22-31. https://doi.org/10.1016/j.rasd.2008.03.002

Pan, C. Y. (2010). Effects of water exercise swimming program on aquatic skills and social behaviors in children with autism spectrum disorders. Autism, 14, 9-28. https://doi.org/10.1177/1362361309339496

Pan, C. Y. (2011). The efficacy of an aquatic program on physical fitness and aquatic skills in children with and without autism spectrum disorders. Research in Autism Spectrum Disorders, 5(1), 657-665. https://doi.org/10.1016/j.rasd.2010.08.001

Pan, C. Y., Tsai, C. L., \& Hsieh, K. W. (2011). Physical activity correlates for children with autism spectrum disorders in middle school physical education. Research quarterly for exercise and sport, 82(3), 491-498. https://doi.org/10.1080/02701367.2011.10599782

Prupas, A., \& Reid, G. (2001). Effects of exercise frequency on stereotypic behaviors of children with developmental disabilities. Education and Training in Mental Retardation and Developmental Disabilities, 36(2), 196-206.

Reid, G., \& O'Connor, J. (2003). The autism spectrum disorders. Palaestra, 19(1), 20-26.

Sandt, D. D. R., \& Frey, G. C. (2005). Comparison of physical activity levels between children with and without autistic spectrum disorders. Adapted Physical Activity Quarterly, 22(2), 146-159. https://doi.org/10.1123/apaq.22.2.146

Todd, T., \& Reid, G. (2006). Increasing physical activity in individuals with autism. Focus on Autism and Other Developmental Disabilities, 21, 167-176. https://doi.org/10.1177/10883576060210030501

United Nations Educational, Scientific and Cultural Organization. [UNESCO] (1994). The Salamanca ftatement and framework for action on special needs education. World Conference on Special Needs Education: Access and Quality. Salamanca, Spain, 7-10 June.

Wang, S. Y., Cui, Y., \& Parrila, R. (2011). Examining the effectiveness of peer-mediated and video-modeling social skills interventions for children with autism spectrum disorders: A meta-analysis in single-case research using HLM. Research in Autism Spectrum Disorders, 5(1), 562-569. https://doi.org/10.1016/j.rasd.2010.06.023

Yanardag, M., Ergun, N., Yilmaz, İ., Aras, O., \& Konukman, F. (2011). Effects of water exercise program on motor performance in autism. Research Quarterly for Exercise and Sport, 82(1), 76-84.

Yanardağ M., Ergun N., Yılmaz İ., \& Konukman F. (2008). Effects of most to least prompting procedure on ball playing. Research Quarterly for Exercise and Sport, 79(1), 87-91.

Yanardağ, M., Ergun N., \& Yılmaz, İ. (2009). Effects of adapted exercise education on physical fitness in childeren with autism. Turkish Journal of Physiotherapy Rehabilitation, 20, 25-31.

Yarımkaya, E., İlhan, E. L., \& Karasu, N. (2017). An investigation of the changes in the communication skills of an individual with autism spectrum disorder participating in peer mediated adapted physical activities. Ankara University Faculty of Educational Sciences Journal of Special Education, 18(02), 225-252.

Yavuzer, H. (2002). Çocuk Psikolojisi (Child Psychology), (22nd ed). İstanbul, Remzi Publishing.

Yılmaz, İ., Yanardağ, M., Birkan, B. A., \& Bumin, G. (2004). Effects of swimming training on physical fitness and water orientation in autism. Pediatrics International, 46(5), 624-626.

https://doi.org/10.1111/j.1442-200x.2004.01938.x

\section{Copyrights}

Copyright for this article is retained by the author(s), with first publication rights granted to the journal.

This is an open-access article distributed under the terms and conditions of the Creative Commons Attribution license which permits unrestricted use, distribution, and reproduction in any medium, provided the original work is properly cited. 